Acta Crystallographica Section F

Structural Biology

and Crystallization

Communications

ISSN 1744-3091

Chao $\mathrm{Yu},{ }^{\mathrm{a}} \ddagger$ Max Crispin, ${ }^{\mathrm{b}} \neq$ Andreas F.-P. Sonnen, ${ }^{\mathbf{C}} ¥$ David J. Harvey, ${ }^{b}$ Veronica T. Chang, ${ }^{a}$ Edward J. Evans, ${ }^{a}$ Christopher N. Scanlan, ${ }^{\text {b David I. Stuart, }}{ }^{\text {C }}$ Robert J. C. Gilbert ${ }^{\mathrm{c}}$ and Simon J. Davis $^{\text {a* }}$

${ }^{\mathbf{a}}$ Nuffield Department of Clinical Medicine, University of Oxford, John Radcliffe Hospital, Headington, Oxford OX3 9DS, England, boxford Glycobiology Institute, Department of Biochemistry, University of Oxford, Oxford OX1 1QU, England, and ${ }^{\mathbf{c}}$ Division of Structural Biology, The Henry Wellcome Building for Genomic Medicine, University of Oxford, Roosevelt Drive, Oxford OX3 7BN, England

₹ These authors contributed equally.

Correspondence e-mail:

simon.davis@ndm.ox.ac.uk

Received 23 December 2010

Accepted 10 May 2011

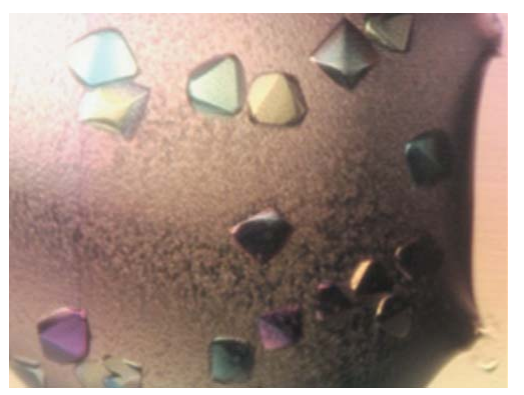

\section{Use of the $a$-mannosidase I inhibitor kifunensine allows the crystallization of apo CTLA-4 homodimer produced in long-term cultures of Chinese hamster ovary cells}

Glycoproteins present problems for structural analysis since they often have to be glycosylated in order to fold correctly and because their chemical and conformational heterogeneity generally inhibits crystallization. It is shown that the $\alpha$-mannosidase I inhibitor kifunensine, which has previously been used for the purpose of glycoprotein crystallization in short-term (3-5 d) cultures, is apparently stable enough to be used to produce highly endoglycosidase $\mathrm{H}$ sensitive glycoprotein in long-term (3-4 week) cultures of stably transfected Chinese hamster ovary $(\mathrm{CHO})$ cells. Matrix-assisted laser desorption/ionization time-of-flight mass spectrometry-based analysis of the extracellular region of the cytotoxic T-lymphocyte antigen 4 (CTLA-4; CD152) homodimer expressed in long-term $\mathrm{CHO}$ cell cultures in the presence of kifunensine revealed that the inhibitor restricted CTLA-4 glycan processing to $\mathrm{Man}_{9} \mathrm{GlcNAc}_{2}$ and $\mathrm{Man}_{5} \mathrm{GlcNAc}_{2}$ structures. Complex-type glycans were undetectable, suggesting that the inhibitor was active for the entire duration of the cultures. Endoglycosidase treatment of the homodimer yielded protein that readily formed orthorhombic crystals with unit-cell parameters $a=43.9, b=51.5, c=102.9 \AA$ and space group $P 2_{1} 2_{1} 2_{1}$ that diffracted to Bragg spacings of $1.8 \AA$. The results indicate that kifunensine will be effective in most, if not all, transient and longterm mammalian cell-based expression systems.

\section{Introduction}

Protein glycosylation generally inhibits the crystallization of glycoproteins, but is often required for their correct folding (reviewed by Davis \& Crispin, 2011). Our initial solutions to the glycosylation problem involved the use of long-term Chinese hamster ovary ( $\mathrm{CHO}$ ) cell-based expression systems in which folding and initial glycosylation of the glycoprotein were allowed to proceed normally but the subsequent processing of the $\mathrm{N}$-linked glycans was restricted in a way that allowed their enzymatic removal from the purified glycoprotein with endoglycosidase H (Endo H; Davis et al., 1993, 1995; Butters et al., 1999). Endo H cleaves between the GlcNAc residues in the di$N$-acetylchitobiose core of oligomannose-type and hybrid-type $\mathrm{N}$-glycans, leaving single $\beta$-GlcNAc residues at each glycosylation sequon. To implement these methods in a high-throughput (i.e. structural-genomics-based) setting, we explored the use of glycosylation processing inhibitors in cells that can be transiently transfected, such as human embryonic kidney (HEK) 293T cells (Chang et al., 2007). This required the use of inhibitors that are likely to circumvent the endomannosidase-based shunt pathway present in HEK 293T cells, which currently provide the benchmark for high-level transient mammalian protein expression (Chang et al., 2007). We found that glycoproteins expressed in 3-5 d cultures of HEK 293T cells in the presence of relatively low levels of the $\alpha$-mannosidase I inhibitor kifunensine exhibited high levels of sensitivity to Endo $\mathrm{H}$ without compromising overall expression yields. Although the general effects of kifunensine and other alkaloid-like processing inhibitors have been very well established (Elbein, 1991), for the most part this information has come from biochemical analyses of relatively short-term cultures. Following culture for $12 \mathrm{~d}$ in the presence of 
kifunensine, recombinant human immunoglobulin expressed in $\mathrm{CHO}$ cells was shown to contain 'mainly' oligomannose-type N-glycans (van Berkel et al., 2010), but the ability of kifunensine to efficiently inhibit glycan processing for periods beyond this was unknown.

Not all proteins of structural interest are amenable to highthroughput expression in transient cultures and our previous work with long-term stable expression systems involved the use of difficultto-transfect cells or hard-to-obtain glycosylation inhibitors (Davis \& Crispin, 2011). The apo form of the homodimeric extracellular region of human cytotoxic T-lymphocyte antigen 4 (CTLA-4; CD152), the product of the CTLA4 gene and a critical modulator of human immune responses (Fife \& Bluestone, 2008), refolds incorrectly from bacterial inclusion bodies (Sonnen et al., 2010) and is usually expressed as an immunoglobulin Fc fusion protein to effect faithful dimerization, which compromises yields. We show that kifunensine is an effective inhibitor of $\mathrm{N}$-glycan processing in long-term (3-4 week) cultures of $\mathrm{CHO}$ cells and use this method to obtain high-quality crystals of the apo CTLA-4 homodimer. Our results suggest that kifunensine will be effective in most, if not all, short-term and longterm mammalian cell expression systems. Analysis of the crystals of the CTLA-4 homodimer has provided key insights into the structural basis of triggering of this important receptor (Yu et al., 2010).

\section{Methods}

\subsection{Protein expression}

Chimeric cDNA encoding, in the following order, residues 1-161 of the extracellular (ex) region of human CTLA-4, including the signal peptide sequence, a thrombin cleavage site, the heavy-chain constant domains 2 and 3 of murine $\mathrm{IgG} 1(\mathrm{Fc})$ and a C-terminal Lys-His ${ }_{6}$ tag was cloned into the pEE14 expression vector (Bebbington \& Hentschell, 1987; Davis et al., 1990). The expression vector encoding the chimeric CTLA-4-Fc-Lys-His ${ }_{6}$ construct (abbreviated to CTLA$4 \mathrm{exFc}$ ) was then transfected into $\mathrm{CHO}-\mathrm{K} 1$ cells followed by clone selection with $25 \mu M$ methionine sulfoximine. Among the surviving clones, one expressed CTLA-4exFc at a level of approximately $15 \mathrm{mg} \mathrm{l}^{-1}$ and this was used for protein production in large-scale cultures (Cell Factories; Nunc, Roskilde, Denmark) in the presence of $10 \mu M$ kifunensine (Toronto Research Chemicals, North York, Ontario, Canada) for up to three weeks following the addition of $2 \mathrm{~m} M$ sodium butyrate to boost expression.

\subsection{Protein purification and crystallization}

The CTLA-4exFc was harvested after 3-4 weeks of culture and the protein was extracted by metal-chelate chromatography using $\mathrm{Ni}-$ NTA agarose (Qiagen, West Sussex, England). The CTLA-4exFc was eluted from the Ni-NTA agarose with $250 \mathrm{~m} M$ imidazole in $20 \mathrm{mM}$ Tris- $\mathrm{HCl}, 0.5 \mathrm{M} \mathrm{NaCl} \mathrm{pH} 8.0$ and further purified by size-exclusion chromatography (Superdex 200 HR 10/30 column; GE Healthcare, Amersham, England). Removal of the Fc from CTLA-4exFc, yielding residues 1-126 of the mature CTLA-4 polypeptide followed by the Leu-Val-Pro-Arg sequence from the cleaved thrombin site, was achieved by treating the protein with thrombin in $10 \mathrm{~m} M$ HEPES, $150 \mathrm{~m} M \mathrm{NaCl} \mathrm{pH} 7.4$ at room temperature for $16 \mathrm{~h}$. Non-Ni-NTAagarose-bound (i.e. cleaved) CTLA-4ex homodimer was bufferexchanged to $10 \mathrm{~m} M$ HEPES, $150 \mathrm{~m} M \mathrm{NaCl} \mathrm{pH} 7.4$ and deglycosylated with Endo $\mathrm{H}_{\mathrm{f}}$ (New England Biolabs, Hitchin, England) at room temperature for $3 \mathrm{~h}$. The deglycosylated Endo $\mathrm{H}_{\mathrm{f}}$-treated CTLA-4ex homodimer was purified by lectin-affinity chromatography and gel filtration as previously described (Davis et al., 1995).
Initial conditions for CTLA-4ex homodimer crystallization were screened using a sparse-matrix crystallization screening kit at $295 \mathrm{~K}$ (Hampton Research, Laguna Niguel, California, USA). Droplets $(100 \mathrm{nl})$ of protein at $14.5 \mathrm{mg} \mathrm{ml}^{-1}$ in $10 \mathrm{~m} M$ HEPES, $150 \mathrm{mM} \mathrm{NaCl}$ pH 7.4 were mixed with $100 \mathrm{nl}$ reservoir solution and set up in 96-well plates as described previously (Walter et al., 2005). Following freezing of the crystals in glycerol/precipitant, diffraction data were collected on beamline I04 of the Diamond Light Source, England. Data were processed and scaled with the $H K L$ suite (Otwinowski \& Minor, 1997).

\subsection{Glycan analysis and structural assignment}

Glycans were released using protein $N$-glycanase (PNGase) $\mathrm{F}$ (Küster et al., 1997) for analysis by positive-ion matrix-assisted laser desorption/ionization (MALDI) time-of-flight (TOF) mass spectrometry (MS) and negative-ion electrospray ionization (ESI) MS. Bands from Coomassie Blue-stained SDS-PAGE gels containing approximately $10 \mu \mathrm{g}$ target glycoprotein were excised and eluted with alternating water/acetonitrile washes, dried and rehydrated with $30 \mu \mathrm{l}$ $30 \mathrm{mM} \mathrm{NaHCO} 3$ pH 7.0 containing 100 units $\mathrm{ml}^{-1}$ of PNGase $\mathrm{F}$ (Prozyme, San Leandro, California, USA). The released N-linked glycans were eluted and cleaned with a Nafion 117 membrane (Börnsen et al., 1995) prior to mass spectrometry. Positive-ion MALDI-TOF mass spectra were recorded with a Shimazu AXIMA TOF $^{2}$ MALDI TOF/TOF mass spectrometer (Shimadzu-Kratos, Manchester, England) fitted with delayed extraction and a nitrogen laser $(337 \mathrm{~nm})$. Samples were prepared by adding $0.5 \mu \mathrm{l}$ of an aqueous solution of the glycans to the matrix solution $[0.3 \mu \mathrm{l}$ of a saturated solution of recrystallized 2,5-dihydroxybenzoic acid in $1: 1(v: v)$ acetonitrile:water containing a trace of sodium chloride] on the stainless-steel target plate and allowing it to dry at room temperature, followed by recrystallization from ethanol.

MALDI mass spectra of the glycans from the CTLA-4 glycoforms revealed compositional information by the identification of $(M+\mathrm{Na})^{+}$ions, whilst the structural assignment of the ions was achieved by negative-ion ESI MS using a Waters quadrupole time-offlight (Q-Tof) Ultima Global instrument (Waters MS Technologies, Manchester, England). For ESI MS, samples in 1:1(v:v) methanol: water were infused through Proxeon nanospray capillaries (Proxeon Biosystems, Odense, Denmark). The ion-source conditions were as follows: temperature, $393 \mathrm{~K}$; nitrogen flow, $50 \mathrm{l} \mathrm{h}^{-1}$; infusion needle potential, $1.1 \mathrm{kV}$; cone voltage, $100 \mathrm{~V}$; RF-1 voltage, $180 \mathrm{~V}$. For MS/MS data acquisition, the parent ion was selected at low resolution to allow transmission of isotope peaks and was fragmented with argon at a pressure of $100 \mathrm{~Pa}$. Instrument control, data acquisition and processing were performed with MassLynx software v.4.1 (Waters). Fragmentation spectra were analyzed as described previously (Harvey, 2005a,b,c,d; Harvey et al., 2008). The nomenclature used follows that of Domon \& Costello (1988) and is distinct from the established labels of the branches of the oligomannose-type glycans D1-D3.

\section{Results}

3.1. Expression and crystallization of CTLA-4ex from CHO-K1 cells cultured with kifunensine

CTLA-4ex homodimer was prepared from the supernatants of long-term (3-4 week) cultures of CHO-K1 cells grown in the presence of kifunensine. Preliminary optimization utilizing a chimeric Fc-fusion protein containing the extracellular region of the programmed death 1 (PD-1) protein indicated that the lowest 
concentration of kifunensine ensuring largely complete Endo Hsensitivity following expression in CHO-K1 cells was $10 \mu M$ (data not shown). To compare the sensitivity of CTLA-4ex generated in the presence of kifunensine versus other approaches, we also prepared CTLA-4ex from untreated CHO-K1 cells, from CHO-K1 cells treated with the $\alpha$-glucosidase I inhibitor $N$-butyldeoxynojirimycin (NBDNJ; Davis et al., 1995), from mutant CHO-derived Lec3.2.8.1 cells whose ability to process glycans beyond the $\mathrm{Man}_{5} \mathrm{GlcNAc}_{2}$ stage is severely limited (Davis et al., 1993) and from Lec3.2.8.1 cells treated with NB-DNJ (Butters et al., 1999). Whereas the CHO-K1 cellderived CTLA-4ex was completely resistant to Endo $\mathrm{H}$, all other forms exhibited varying degrees of sensitivity, with protein expressed in Lec3.2.8.1 cells and in CHO-K1 cells, both with NB-DNJ, exhibiting the greatest and least sensitivity, respectively (Fig. 1a). CTLA-4ex expressed in the presence of kifunensine, and in Lec3.2.8.1 cells only, exhibited similar intermediate levels of sensitivity. The sensitivity of CTLA-4ex expressed in CHO-K1 cells in the presence of kifunensine during 3-4 week cultures was comparable to that observed for proteins expressed in short-term (i.e. 2-3 d) cultures of HEK 293 T cells in the presence of the inhibitor (Chang et al., 2007).

Crystals of deglycosylated lectin-purified CTLA-4ex grew in a variety of conditions: (i) $25 \%(w / v)$ polyethylene glycol 1500 in $0.1 \mathrm{M}$ sodium propionate/sodium cacodylate/Bis-Tris propane buffer $\mathrm{pH}$ 6.0 ; (ii) $0.2 \mathrm{M}$ sodium dihydrogen phosphate, $25 \%(\mathrm{w} / \mathrm{v})$ polyethylene glycol 3350; (iii) $30 \%(w / v)$ polyethylene glycol $6000,0.1 M$ citrate $\mathrm{pH}$ 5.0 and (iv) $0.2 \mathrm{M}$ ammonium acetate, $25 \%(w / v)$ polyethylene glycol 1500, $0.1 M$ Bis-Tris pH 5.5. Examples of crystals are shown in Figs. $1(b)$ and $1(c)$. The best diffraction observed was to $1.8 \AA$ resolution, but the diffraction had a high background and contained a
Table 1

Data-collection and processing statistics.

Values in parentheses are for the highest resolution shell.

\begin{tabular}{ll}
\hline No. of crystals & 1 \\
Beamline & $\mathrm{I} 04$ \\
Wavelength $(\AA)$ & 0.9697 \\
Detector & ADSC Q315r \\
Crystal-to-detector distance $(\mathrm{mm})$ & 270 \\
Rotation range per image $\left({ }^{\circ}\right)$ & 0.75 \\
Total rotation range $\left({ }^{\circ}\right)$ & 264.75 \\
Exposure time per image $(\mathrm{s})$ & 0.8 \\
Resolution range $(\AA)$ & $25-1.8(2.0-1.8)$ \\
Space group & $P 2_{1} 2_{1} 2_{1}$ \\
Unit-cell parameters $(\AA)$ & $a=43.9, b=51.5, c=102.9$ \\
Mosaicity $\left({ }^{\circ}\right)$ & 0.291 \\
Total No. of measured intensities & 211670 \\
Unique reflections & $22222(5907)$ \\
Multiplicity & $9.52(8.23)$ \\
Mean $I / \sigma(I)$ & $10.33(3.19)$ \\
Completeness $(\%)$ & $99.7(99.4)$ \\
$R_{\text {merge }}(\%) \dagger$ & $11.1(33.8)$ \\
$R_{\text {meas }}$ or $R_{\text {r.i.m. }}(\%)$ & $18.3(70.8)$ \\
Overall $B$ factor from Wilson plot $\left(\AA^{2}\right)$ & 36.803 \\
\hline
\end{tabular}

$\dagger R_{\text {merge }}=\sum_{h k l} \sum_{i}\left|I_{i}(h k l)-\langle I(h k l)\rangle\right| / \sum_{h k l} \sum_{i} I_{i}(h k l)$, where $I_{i}(h k l)$ is the $i$ th observation of reflection $h k l$ and $\langle I(h k l)\rangle$ is the weighted average intensity for all observations $l$ of reflection $h k l$.

good number of split spots with high mosaicity. However, diffraction was improved by scaling up the drop volume from $200 \mathrm{nl}$ to $2 \mu \mathrm{l}$ and by using the traditional sitting-drop vapour-diffusion method (Harlos et al., 1992). The self-rotation function and a Harker section of the native Patterson function clearly established that the space group is $P 2_{1} 2_{1} 2_{1}$ (data not shown). Data-collection and processing statistics are given in Table 1.

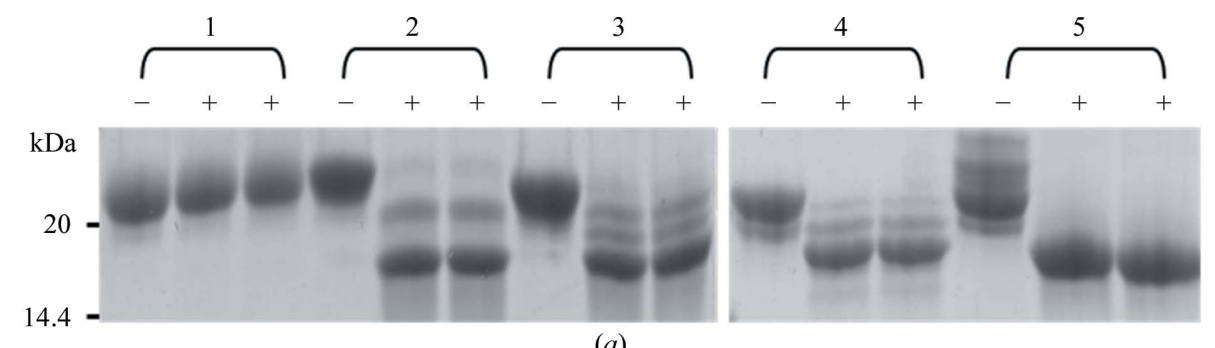

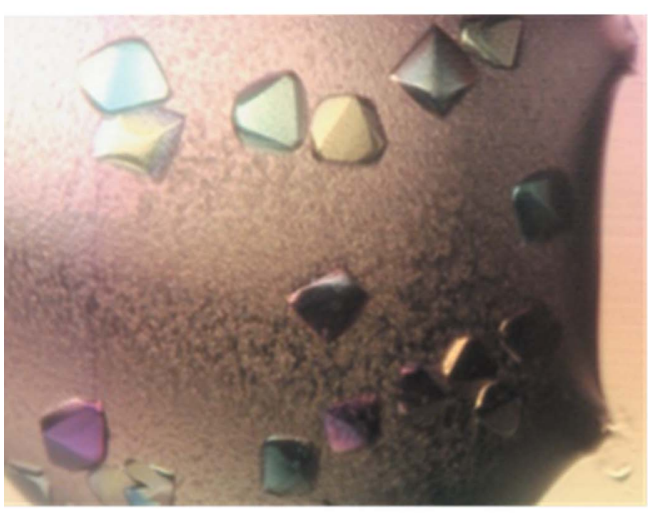

(b)

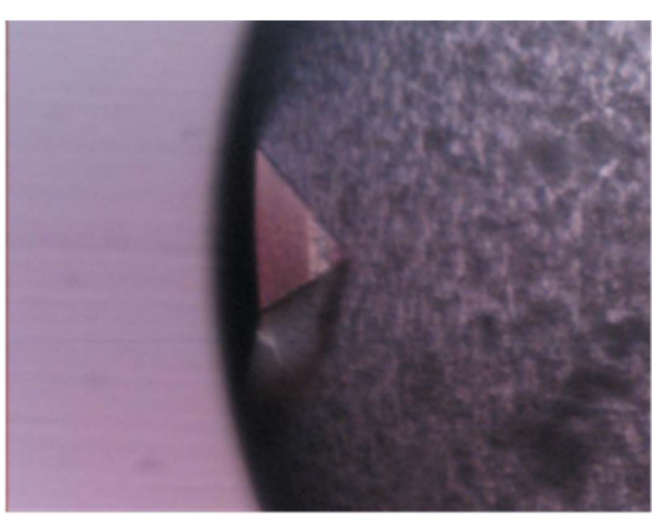

(c)

Figure 1

Deglycosylation and crystallization of the apo CTLA-4 homodimer. (a) Coomassie-stained SDS-polyacrylamide gel run under reducing conditions showing undigested ( - ) and Endo H-digested (+) CTLA-4ex expressed in wild-type and mutant CHO cells with and without glycan-processing inhibitors. Samples in the left and right lanes marked with (+) were Endo $\mathrm{H}$-digested for 1 and $3 \mathrm{~h}$, respectively, in order to confirm that after $1 \mathrm{~h}$ the reaction had proceeded to completion. Sample 1, CHO-K1 cells only; sample 2, CHO-K1 cells with $1.5 \mathrm{~m} M$ NB-DNJ; sample 3, CHO-K1 cells with $10 \mu M$ kifunensine; sample 4, CHO Lec3.2.8.1 cells only; sample 5, CHO Lec3.2.8.1 cells with 0.5 mM NB-DNJ. In $(b)$ crystals were grown in $25 \%(w / v)$ polyethylene glycol 1500 in $0.1 M$ sodium propionate/sodium cacodylate/Bis-Tris propane buffer $\mathrm{pH} 6.0$ (Molecular Dimensions). These crystals were $\sim 100 \times 100 \times 100 \mu \mathrm{m}$ in size. The crystal shown in $(c)$ was grown in $0.2 \mathrm{M}$ ammonium acetate, $25 \%(w / v)$ polyethylene glycol $1500,0.1 M$ Bis-Tris pH 5.5 (Hampton Research). This crystal was $\sim 100 \times 200 \times 100 \mu \mathrm{m}$ in size. 


\subsection{Effects of kifunensine on glycan processing in $\mathrm{CHO}-\mathrm{K} 1$ cells}

The glycans released from CTLA-4ex homodimers expressed under the five sets of conditions were analyzed by MALDI-TOF and ESI mass spectrometry. The MALDI mass spectrum for N-linked glycans from CTLA-4ex from CHO-K1 cells cultured with $1.5 \mathrm{mM}$ NB-DNJ revealed a dominant peak at $\mathrm{m} / \mathrm{z} 2067$ corresponding to $\mathrm{Hex}_{10} \mathrm{HexNAc}_{2}$ (Fig. 2a). This composition can be assigned to the specific isomer $\mathrm{Glc}_{3} \mathrm{Man}_{7} \mathrm{GlcNAc}_{2}$ by the collision-induced decomposition (CID) spectrum of the corresponding $(M+\mathrm{Cl})^{-}$ion, which revealed diagnostic ions for the trimannosyl 6-antennae $\left(\mathrm{C}_{3 \alpha}\right.$ and $\mathrm{C}_{3 \beta}$ at $\mathrm{m} / \mathrm{z} 503.1$ and the $\mathrm{D}$ and $\mathrm{D}-18$ ions at 647.2 and 629.2 , respectively) and the 3-antennae $\left({ }^{1,3} \mathrm{~A}_{5}\right.$ and ${ }^{2,4} \mathrm{~A}_{5}$ ions at $\mathrm{m} / \mathrm{z}, 707.2$ and ${ }^{1,3} \mathrm{~A}_{6}$ and ${ }^{2,4} \mathrm{~A}_{6}$ at $m / z$ 869.2) (Supplementary Fig. S1 $a^{\mathbf{1}}$ ). This structure is consistent with the almost complete inhibition of processing by $\alpha$-glucosidase I achieved at $1.5 \mathrm{~m} M$ and matches that previously reported for glycoproteins expressed in CHO-K1 cells with high levels of NB-DNJ (Butters et al., 1999; Crispin et al., 2006). The ${ }^{2,4} \mathrm{~A}_{8}$, $\mathrm{B}_{8}$ and ${ }^{2,4} \mathrm{~A}_{8}$ ions and corresponding ions in the other spectra shown in Supplementary Fig. S1 $(a)^{\mathbf{1}}$ are diagnostic for the mannosylchitobiose trisaccharide core and show no substitutions in this region of the molecule.

For glycans derived from CHO Lec3.2.8.1 cells in the presence of $0.5 \mathrm{~m} M$ NB-DNJ (Fig. $2 b$ ) the dominant ion at $\mathrm{m} / \mathrm{z}, 2067.9$ gave a CID spectrum indicating $\mathrm{Glc}_{3} \mathrm{Man}_{7} \mathrm{GlcNAc}_{2}$ as above. The corresponding spectrum of the ion at $\mathrm{m} / \mathrm{z} 1257.6$ was identical to that from a reference sample of $\mathrm{Man}_{5} \mathrm{GlcNAc}_{2}$. The spectrum of the ion at $\mathrm{m} / \mathrm{z}$ 1743.8 corresponding to $\mathrm{Hex}_{8} \mathrm{HexNAc}_{2}$ is shown in Supplementary Fig. $\mathrm{S} 1(b)^{\mathbf{1}} . \mathrm{B}_{3 \beta}, \mathrm{C}_{3 \beta},{ }^{0,3} \mathrm{~A}_{7}, \mathrm{D}-18$ and $\mathrm{D}$ ions at $m / z$ 485, 503, 575, 629 and 647, respectively, showed the presence of the $\mathrm{Man}_{3}$-containing 6-antenna. The other four hexose residues must therefore comprise the 3-antenna and consist of $\mathrm{Glc}_{1} \mathrm{Man}_{3}$. This conclusion was supported by the ions at $\mathrm{m} / \mathrm{z} 545,383$ and 323, which were specific to the 3 -antenna and $2 \times 162$ mass units lower than their counterparts in the spectrum of $\mathrm{Glc}_{3} \mathrm{Man}_{7} \mathrm{GlcNAc}_{2}$.

In the MALDI-TOF spectrum for glycans from CHO-K1 cells in the presence of $10 \mu M$ kifunensine (Fig. $2 c$ ), compounds producing the ions at $\mathrm{m} / \mathrm{z} 1905.7$ and 1257.5 gave CID spectra showing the normal $\mathrm{Man}_{9} \mathrm{GlcNAc}_{2}$ and $\mathrm{Man}_{5} \mathrm{GlcNAc}_{2}$ structures. The spectrum of $\mathrm{Man}_{9} \mathrm{GlcNAc}_{2}$ is shown in Supplementary Fig. S1 $(c)^{\mathbf{1}} . \mathrm{B}_{3 \beta}, \mathrm{C}_{3 \beta},{ }^{0,3} \mathrm{~A}_{7}$, $\mathrm{D}-18$ and $\mathrm{D}$ ions at $\mathrm{m} / \mathrm{z} 809,827,899,953$ and 971 , respectively, confirmed the $\mathrm{Man}_{5}$ structure of the 6-antenna. The corresponding CID spectrum of the compound with the composition $\mathrm{Hex}_{8} \mathrm{HexNAc}_{2}$ $(\mathrm{m} / \mathrm{z} 1743.7$ in the MALDI-TOF spectrum) is shown in Supplementary Fig. S1 $(d)^{\mathbf{1}}$. Its CID spectrum contained $\mathrm{B} 3 \beta, \mathrm{C}_{3 \beta},{ }^{0,3} \mathrm{~A}_{7}$, $\mathrm{D}-18$ and $\mathrm{D}$ ions at the same masses as those in the spectrum of $\mathrm{Man}_{9} \mathrm{GlcNAc}_{2}$, indicating a Man ${ }_{5}$-containing 6-antenna and showing that a mannose was missing from the 3 -antenna. The isomeric $D 1, D 3$ $\mathrm{Man}_{8} \mathrm{GlcNAc}_{2}$ that is the normal product of the first exomannosidase cleavage gave the spectrum shown in Supplementary Fig. S1 $(e)^{\mathbf{1}}$. The presence of one fewer mannose residue in the 6-antenna is reflected by the masses of the $\mathrm{B}_{3 \beta}, \mathrm{C}_{3 \beta},{ }^{0,3} \mathrm{~A}_{7}, \mathrm{D}-18$ and $\mathrm{D}$ ions, which are 162 units lower than in the spectrum of the isomer shown in Supplementary Fig. S1 $(d)^{\mathbf{1}}$. Complex-type structures were undetectable in the spectrum from kifunensine-treated cells. The MALDI-TOF spectrum for glycans released from CTLA-4ex expressed in $\mathrm{CHO}$ Lec3.2.8.1 cells (Fig. 2d) revealed the production of only $\mathrm{Man}_{5} \mathrm{GlcNAc}_{2}$, whereas the spectrum for protein from untreated CHO-K1 cells (Fig. 2e) showed complex-type glycans, explaining its unreactivity towards Endo $\mathrm{H}$.

\footnotetext{
${ }^{1}$ Supplementary material has been deposited in the IUCr electronic archive (Reference: BW5387).
}

\section{Discussion}

Since kifunensine targets highly conserved class I mannosidases downstream of the endomannosidase-dependent shunt pathway, our expectation was that it might be effective in a number of mammaliancell-based expression systems (Chang et al., 2007; Nettleship et al., 2009). It was not obvious, however, that kifunensine was sufficiently stable in very long-term (e.g. 3-4 week) stable cultures versus shortterm (2-3 d) transient cultures to affect the glycan processing of all the glycoprotein produced during extended culture. However, we succeeded in producing glycoprotein that could be very efficiently deglycosylated with Endo $\mathrm{H}$ even from cultures kept for as long as four weeks. The glycan analysis was notable for the complete absence of detectable complex-type glycans in the sample prepared in the presence of kifunensine, suggesting either that the inhibitor is stable for the entire period of the culture or that the cells only express
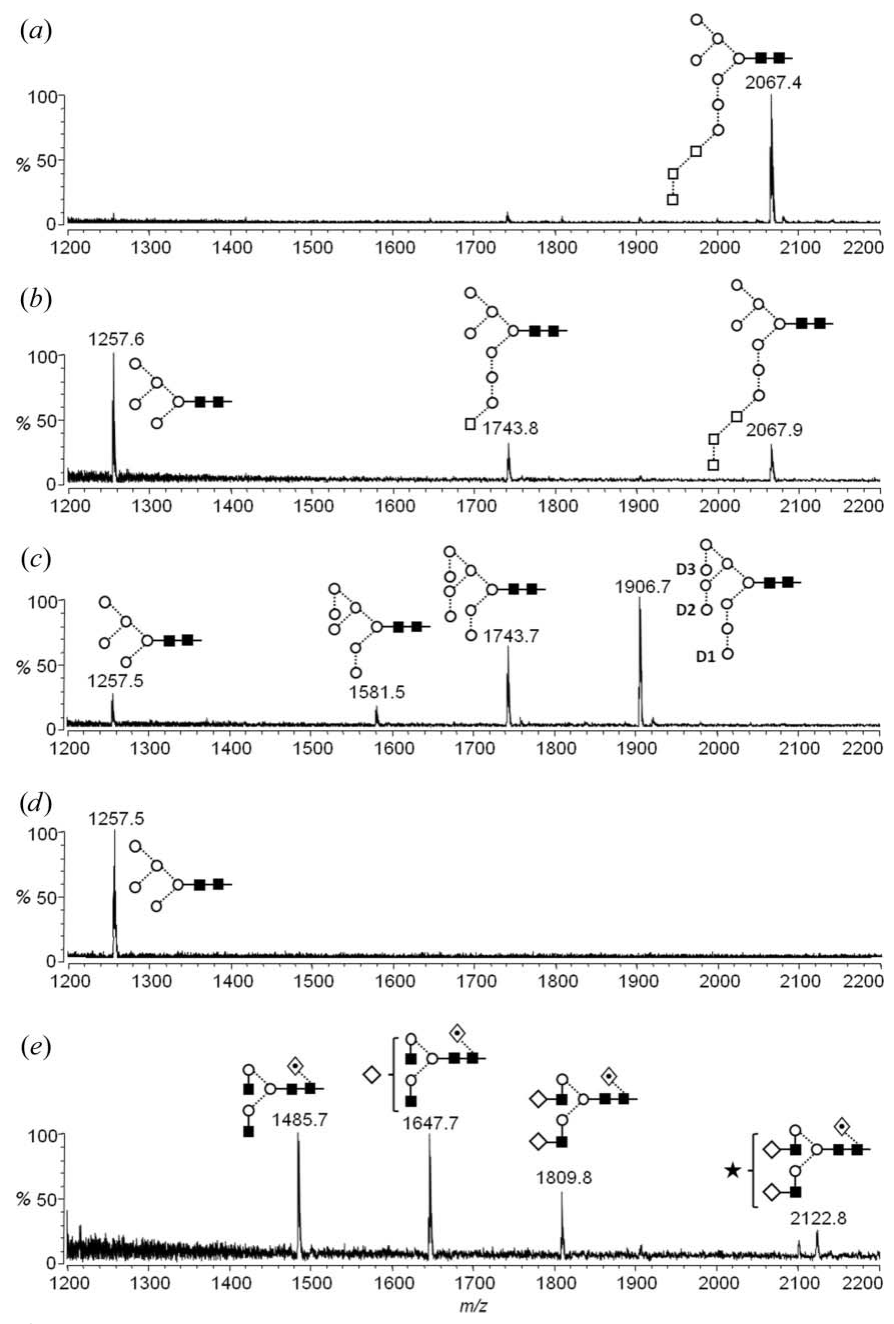

Figure 2

Positive-ion MALDI-TOF mass spectra of N-linked glycans from glycoforms of CTLA-4ex expressed in CHO-K1 cells with 1.5 $\mathrm{m} M$ NB-DNJ (a), CHO Lec3.2.8.1 cells with $0.5 \mathrm{~m} M$ NB-DNJ (b), CHO-K1 cells with $10 \mu M$ kifunensine $(c)$, CHO Lec3.2.8.1 cells $(d)$ and CHO-K1 cells $(e)$. A trace amount of putative $\mathrm{Man}_{3} \mathrm{GlcNAc}_{2}$ and $\mathrm{Man}_{4} \mathrm{GlcNAc}_{2}$ glycans was detected in the spectra of CHO Lec3.2.8.1 but was obscured by contaminating peaks (not shown). Symbols used for the structural formulae: diamonds, Gal; filled diamonds, GalNAc; filled squares, GlcNAc; circles, Man; stars, sialic acid; diamonds with dots in, Fuc. The linkage position is shown by the angle of the lines linking the sugar residues (vertical line, 2link; forward slash, 3-link; horizontal line, 4-link; back slash, 6-link), whilst the anomericity is indicated by full lines for $\alpha$-bonds and broken lines for $\beta$-bonds (Harvey et al., 2009). 
protein for a brief period during which the inhibitor is active. Analysis of the kinetics of expression of other proteins, in which the cells secrete the heterologous gene product for the lifetime of the culture (S. J. Davis et al., unpublished work), supports the former possibility. Although we did not directly examine the effect of kifunensine on the levels of expression of CTLA-4ex, we previously showed that transiently transfected HEK 293T cells treated with the inhibitor produced $30 \%$ more protein than untreated cells, presumably owing to effects on ER-associated degradation (Chang et al., 2007). At present, we have no reason to suspect that this will not also be the case for $\mathrm{CHO}$ cells.

We undertook the structural analysis of unliganded CTLA-4ex in order to determine, via comparisons with ligand-bound complexes of CTLA-4 (Schwartz et al., 2001; Stamper et al., 2001), whether conformational changes accompany ligand-induced triggering of the receptor. The unusual situation arose that details of the crystallization of bacterially expressed human CTLA-4ex have been reported (Chang et al., 2000), but the structure was not subsequently published. Similarly, Schwartz and coworkers referred in passing to having determined the structure of the apo form of CTLA-4ex in their study of the complex of CTLA-4 with domain 1 of B7-2, but did not subsequently publish their observations (Schwartz et al., 2001). We found that apo CTLA-4 monomers expressed in bacteria according to the method of Chang et al. (2000) formed strandexchanged dimers during crystallization (Sonnen et al., 2010). Mammalian cell-expressed material, on the other hand, yielded very high-quality crystals of an apo CTLA-4 homodimer lacking the strand exchange and is, we assume, natively folded owing to its similarities to ligand-bound CTLA-4 (Schwartz et al., 2001; Stamper et al., 2001). The new structure of the apo form of CTLA-4 produced as described here confirms that conformational rearrangements do not accompany ligand binding by the CTLA-4 homodimer (Yu et al., 2010). These observations place additional constraints on the mechanism of signalling by receptors dependent on extrinsic tyrosine kinases such as CTLA-4 and the T-cell receptor.

The authors are grateful to the staff of beamline I04 at the Diamond Light Source (Didcot, England) for assistance with crystallographic data collection. SJD is supported by The Wellcome Trust, RJCG is supported by the Royal Society, DIS is supported by the MRC and CNS and MC are supported by the International AIDS Vaccine Initiative (IAVI). We particularly thank IAVI for an equipment grant to CNS for the purchase of the MALDI-TOF mass spectrometer.

\section{References}

Bebbington, C. \& Hentschell, C. (1987). In DNA Cloning III: A Practical Approach, edited by D. M. Glover. Oxford: IRL Press.

Berkel, P. H. van, Gerritsen, J., van Voskuilen, E., Perdok, G., Vink, T., van de Winkel, J. G. \& Parren, P. W. (2010). Biotechnol. Bioeng. 105, 350-357.

Börnsen, K. O., Mohr, M. D. \& Widmer, H. M. (1995). Rapid Commun. Mass Spectrom. 9, 1031-1034.

Butters, T. D., Sparks, L. M., Harlos, K., Ikemizu, S., Stuart, D. I., Jones, E. Y. \& Davis, S. J. (1999). Protein Sci. 8, 1696-1701.

Chang, V. T., Crispin, M., Aricescu, A. R., Harvey, D. J., Nettleship, J. E., Fennelly, J. A., Yu, C., Boles, K. S., Evans, E. J., Stuart, D. I., Dwek, R. A., Jones, E. Y., Owens, R. J. \& Davis, S. J. (2007). Structure, 15, 267-273.

Chang, C. Y., Fenderson, W. H., Lavoie, T. B., Peach, R. J., Einspahr, H. M. \& Sheriff, S. (2000). Acta Cryst. D56, 1468-1469.

Crispin, M., Harvey, D. J., Chang, V. T., Yu, C., Aricescu, A. R., Jones, E. Y., Davis, S. J., Dwek, R. A. \& Rudd, P. M. (2006). Glycobiology, 16, 748-756.

Davis, S. J. \& Crispin, M. (2011). Functional and Structural Proteomics of Glycoproteins, edited by R. Owens \& J. Nettleship, pp. 127-158. Berlin: Springer Verlag.

Davis, S. J., Davies, E. A., Barclay, A. N., Daenke, S., Bodian, D. L., Jones, E. Y., Stuart, D. I., Butters, T. D., Dwek, R. A. \& van der Merwe, P. A (1995). J. Biol. Chem. 270, 369-375.

Davis, S. J., Puklavec, M. J., Ashford, D. A., Harlos, K., Jones, E. Y., Stuart, D. I. \& Williams, A. F. (1993). Protein Eng. 6, 229-232.

Davis, S. J., Ward, H. A., Puklavec, M. J., Willis, A. C., Williams, A. F. \& Barclay, A. N. (1990). J. Biol. Chem. 265, 10410-10418.

Domon, B. \& Costello, C. E. (1988). Glycoconj. J. 5, 397-409.

Elbein, A. D. (1991). FASEB J. 5, 3055-3063.

Fife, B. T. \& Bluestone, J. A. (2008). Immunol. Rev. 224, 166-182.

Harlos, K., Vas, M. \& Blake, C. F. (1992). Proteins, 12, 133-144.

Harvey, D. J. (2005a). J. Am. Soc. Mass Spectrom. 16, 622-630.

Harvey, D. J. (2005b). J. Am. Soc. Mass Spectrom. 16, 631-646.

Harvey, D. J. (2005c). J. Am. Soc. Mass Spectrom. 16, 647-659.

Harvey, D. J. (2005d). Proteomics, 5, 1774-1786.

Harvey, D. J., Merry, A. H., Royle, L., Campbell, M. P., Dwek, R. A. \& Rudd, P. M. (2009). Proteomics, 9, 3796-3801.

Harvey, D. J., Royle, L., Radcliffe, C. M., Rudd, P. M. \& Dwek, R. A. (2008). Anal. Biochem. 376, 44-60.

Küster, B., Wheeler, S. F., Hunter, A. P., Dwek, R. A. \& Harvey, D. J. (1997). Anal. Biochem. 250, 82-101.

Nettleship, J. E., Rahman-Huq, N. \& Owens, R. J. (2009). Methods Mol. Biol. 498, 245-263.

Otwinowski, Z. \& Minor, W. (1997). Methods Enzymol. 276, 307-326.

Schwartz, J. C., Zhang, X., Fedorov, A. A., Nathenson, S. G. \& Almo, S. C. (2001). Nature (London), 410, 604-608.

Sonnen, A. F., Yu, C., Evans, E. J., Stuart, D. I., Davis, S. J. \& Gilbert, R. J. (2010). J. Mol. Biol. 399, 207-213.

Stamper, C. C., Zhang, Y., Tobin, J. F., Erbe, D. V., Ikemizu, S., Davis, S. J., Stahl, M. L., Seehra, J., Somers, W. S. \& Mosyak, L. (2001). Nature (London), 410, 608-611.

Walter, T. S. et al. (2005). Acta Cryst. D61, 651-657.

Yu, C., Sonnen, A. F., George, R., Dessailly, B. H., Stagg, L. J., Evans, E. J., Orengo, C. A., Stuart, D. I., Ladbury, J. E., Ikemizu, S., Gilbert, R. J. \& Davis, S. J. (2010). J. Biol. Chem. 286, 6685-6696. 